\title{
New Reactive Power Sources Dispatch applied to the IEEE 57 Nodes
}

\author{
M.Belazzoug ${ }^{1}$, A.Hellal ${ }^{2}$ and F.Ykhlef ${ }^{3}$ \\ ${ }^{1}$ Electronic and Electrotechnic Laboratery \\ Department of Mecanic, University of Blida, Algeria \\ e-mail: m_belazzoug@yahoo.fr \\ ${ }^{2}$ National Polytechnical School, Algiers, Algeria \\ ${ }^{3}$ LATSI Laboratery, Department of Electronic, University of Blida, Algeria \\ e-mail: f_ykhlef@yahoo.fr
}

\begin{abstract}
This paper deals with a new dispatching and optimisation of reactive power sources in power systems.

The methodology is first based on an optimal movement of existing reactive sources as a first phase, then an optimal investment in a second phase and finally a combination of the two previous phases as the third one [1]. The methodology showed also the advantage of a two levels procedure, considering an initial minimal compensation before minimizing the active losses. The solution of the global non-linear problem is performed using the projected and augmented Lagrange method associated with the reduced gradient and the DFP methods. Simulations are executed on the 57 IEEE Network that results are presented and discussed.
\end{abstract}

\section{Key words}

Reactive power source, optimisation, movement, investment.

\section{Introduction}

Reliability, efficiency and safety are among the main objectives of electrical power systems. Related to these two points, the management of the reactive power sources, use of regulation systems, regulation concepts and automation level as well as regulation coordination differ from one power system to the other. Reactive compensation optimisation, maintaining voltage within permitted limits, is usually made within a tertiary adjustment that duration can reach several minutes. [2]-[6]

Thus, the necessary devices to bring back the voltage to the acceptable operating range are provided by reactive compensation. But the delays in investments, combined to the incidents and increasing loads, induce constraints characterized by a premature saturation of the means of electrical energy production, of transformation and transport, degraded voltage plans and insufficient regulation ranges, unable to face, in most of cases, the different states of power systems.
Thus, in waiting for new investment programs which are planned for limited periods, this study presents an alternative of optimizing the reactive power compensation by a movement of the power sources or some of them, satisfying all system constraints and minimizing also the active power losses.

As one of the main reactive energy planning goals is to ensure viability of the power system in contingency cases, various critical situations are simulated in order to prevent and prepare the power system to face such situations. Although, the planners and operators have the possibility to decide what cases are to be considered for reactive power dispatch, the proposed program gives a proposal solution to almost all changes that can occur to the power system (incident, contingency, load variation, development).

Considering the complexity of the programming problem, the significant number of variables and constraints, the augmented and projected Lagrange method [7] was the most appropriate technique to be used, in partnership with the reduced gradient and QuasiNewton methods [8].

\section{Problem Formulation}

The optimisation problem to treat corresponds to a constrained function minimization. The used criteria procedure recommends first the full use of all existing power reactive sources before investing new reactive sources. The procedure is then a two levels method

- Movement optimisation or investment as a master problem in the first level

- Solution of the operating problem which is the minimisation of the active losses at the second level 
Global problem formulation is given by:

$$
\begin{gathered}
\min _{u, x} D(W) / \min _{u, x} C(W) / \min _{u, x} O(U, X) \\
\text { s.t. }\left\{\begin{array}{l}
G(U, X)=0 \\
H(U, X) \leq 0 \\
U^{\min } \leq U \leq U^{\max } \\
X^{\min } \leq X \leq X^{\max } \\
Z(W) \leq 0
\end{array}\right.
\end{gathered}
$$

Where $D(W)$ represents the optimal reactive sources movement function (level 1), $C(W)$ the total investment cost function (level 2) and $O(U, X)$ the operating cost function.

The three phases corresponding to the three previous objective functions have the same concept but differ in the initial point relative to the available compensation means. However, the first and second phases are related in case that the first does not reach a feasible solution. The third phase is independent as it deals only with the second level of the procedure.

In this study, the second level of the movement and investment phases is applied for several separate study cases $\left(h=1, \ldots, h_{\max }\right)$, i.e, the active losses minimization for each separate study case (Fig. 1). The third phase corresponding to the optimisation of the operating cost function $O(U, X)$ comprises a second level that calculates the minimum active losses for each study case separately ( $h=1, h_{\max }$ ) and the minimum average active losses for all study cases (Fig. 2).

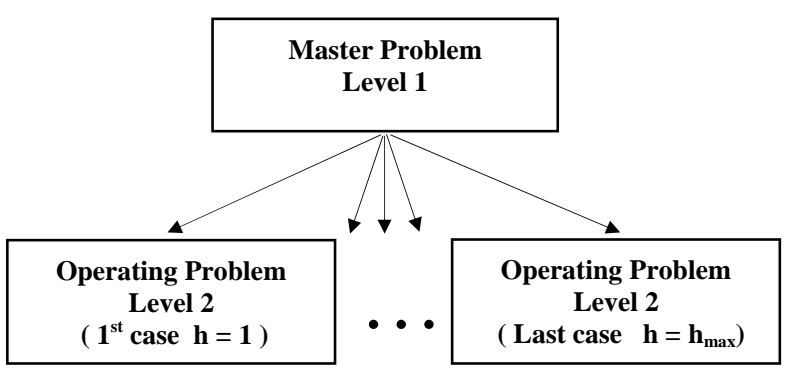

Fig. 1 Problem Decomposition scheme

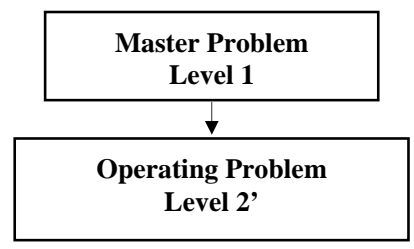

Fig. 2 Other Problem Decomposition scheme

\section{Simulation Results}

In this study, only load nodes are considered compensation node candidates, which is realistic as compensation is generally installed at middle voltage level in power systems for economic and security reasons.

For all tests, the maximum limits of capacitive and inductive compensation to install at node $i$ are equal to 50 Mvars, and the limits on tap changers under load transformers are 0.90 and 1.10. The convergence tolerance for load flow is $10^{-4}$ p.u for active and reactive powers. The optimisation program presents a feasibility and optimality tolerance of $10^{-6}$ p.u.

The studied IEEE 57 nodes network comprises 57 nodes, 63 branches, 15 transformers and 7 controlled nodes. Network data's corresponding to the problem formulation are based on 814 variables and 674 constraints. The voltage limits are as follows:

$$
\begin{aligned}
& 0.98 \text { p.u. } \leq V_{G} \leq 1.10 \text { p.u. } \\
& 0.95 \text { p.u. } \leq V_{C} \leq 1.06 \text { p.u. }
\end{aligned}
$$

Different study cases are considered:

Case 1: base case (nominal point).

Case 2: uniform load variation of $50 \%$ from base case.

Case 3: uniform load variation of $150 \%$ from base case.

Case 4: suppression of line 1-16 and 9-12(incident).

Base case power flow results are given by Table 1 .

TABLE.1 Power Flow Results

\begin{tabular}{|l|c|c|c|c|}
\hline Variables & Case 1 & Case 2 & Case 3 & Case 4 \\
\hline $\mathrm{V}_{\mathrm{G} 1}$ & 1.04 & 1.04 & 1.04 & 1.04 \\
\hline $\mathrm{V}_{\mathrm{G} 2}$ & 1.01 & 1.0222 & 1.01 & 1.01 \\
\hline $\mathrm{V}_{\mathrm{G} 3}$ & 0.985 & 1.0088 & 0.985 & 0.985 \\
\hline $\mathrm{V}_{\mathrm{G} 6}$ & 0.98 & 0.9954 & 0.98 & 0.98 \\
\hline $\mathrm{V}_{\mathrm{G} 8}$ & 1.005 & 1.005 & 1.005 & 1.005 \\
\hline $\mathrm{V}_{\mathrm{G} 9}$ & 0.98 & 0.9997 & 0.98 & 0.9763 \\
\hline $\mathrm{V}_{\mathrm{G} 12}$ & 1.015 & 1.015 & 1.015 & 1.0149 \\
\hline $\mathrm{T}_{9,55}$ & 0.94 & 0.94 & 0.94 & 0.94 \\
\hline $\mathrm{T}_{4,18}$ & 0.97 & 0.97 & 0.97 & 0.97 \\
\hline $\mathrm{T}_{7,29}$ & 0.967 & 0.967 & 0.967 & 0.967 \\
\hline $\mathrm{T}_{10,51}$ & 0.93 & 0.93 & 0.93 & 0.93 \\
\hline $\mathrm{T}_{11,41}$ & 0.955 & 0.955 & 0.955 & 0.955 \\
\hline $\mathrm{T}_{11,43}$ & 0.958 & 0.958 & 0.958 & 0.958 \\
\hline $\mathrm{T}_{13,49}$ & 0.895 & 0.895 & 0.895 & 0.895 \\
\hline $\mathrm{T}_{14,46}$ & 0.9 & 0.9 & 0.9 & 0.9 \\
\hline $\mathrm{T}_{15,45}$ & 0.955 & 0.955 & 0.955 & 0.955 \\
\hline $\mathrm{T}_{20,21}$ & 1.043 & 1.043 & 1.043 & 1.043 \\
\hline $\mathrm{T}_{24,25}$ & 1 & 1 & 1 & 1 \\
\hline $\mathrm{T}_{24,26}$ & 1.043 & 1.043 & 1.043 & 1.043 \\
\hline $\mathrm{T}_{32,34}$ & 0.975 & 0.975 & 0.975 & 0.975 \\
\hline $\mathrm{T}_{39,57}$ & 0.98 & 0.98 & 0.98 & 0.98 \\
\hline $\mathrm{T}_{40,56}$ & 0.958 & 0.958 & 0.958 & 0.958 \\
\hline $\mathrm{QC}_{18}$ (MVars) & \multicolumn{5}{|c|}{10} \\
\hline $\mathrm{QC}_{25}$ (MVars) & \multicolumn{5}{|c|}{5.9} \\
\hline $\mathrm{QC}_{53}$ (MVars) & \multicolumn{5}{|c|}{33.955} \\
\hline $\mathrm{MW}$ losses & 31.1 & 7.23 & 59.36 & 38.13 \\
\hline $\mathrm{MW}$ Losses average & \multicolumn{5}{|l|}{} \\
\hline
\end{tabular}

\section{A. Reactive power sources movement (Phase 1)} 1) Level 1

By moving the battery of the condenser existing with node 53 towards node 31, and 2.1 Mvars of node 18 towards the same node, the stability of the network was checked in its various cases, which also made possible to reduce the average of the active losses of $0.62 \%$, and to readjust all the variables of control and the variables of state. The voltages of load nodes are presented by figures 4-7. Table 2 shows results of level 1 of phase 1 . 
TABLE. 2 Optimisation Results - Level 1- Phase 1

\begin{tabular}{|c|c|c|c|c|}
\hline Variables & Case 1 & Case 2 & Case 3 & Case 4 \\
\hline $\mathrm{V}_{\mathrm{G} 1}$ & 1.0771 & 1.0162 & 1.0836 & 1.0895 \\
\hline $\mathrm{V}_{\mathrm{G} 2}$ & 1.0547 & 1.0006 & 1.0682 & 1.0596 \\
\hline $\mathrm{V}_{\mathrm{G} 3}$ & 1.0630 & 0.9976 & 1.0531 & 1.0304 \\
\hline $\mathrm{V}_{\mathrm{G} 6}$ & 1.0575 & 1.0190 & 1.0684 & 1.0010 \\
\hline $\mathrm{V}_{\mathrm{G} 8}$ & 1.0972 & 1.0677 & 1.0973 & 1.0165 \\
\hline $\mathrm{V}_{\mathrm{G} 9}$ & 1.0622 & 1.0157 & 1.0671 & 1.0037 \\
\hline $\mathrm{V}_{\mathrm{G} 12}$ & 1.0645 & 0.9800 & 1.0648 & 1.0530 \\
\hline$T_{9,55}$ & 0.9000 & 0.9314 & 0.9500 & 0.9484 \\
\hline $\mathrm{T}_{4,18}$ & 1.0259 & 1.0857 & 1.1000 & 0.9899 \\
\hline $\mathrm{T}_{7,29}$ & 1.0144 & 0.9909 & 1.0236 & 1.1000 \\
\hline $\mathrm{T}_{10,51}$ & 1.0186 & 1.1000 & 0.9867 & 1.0063 \\
\hline $\mathrm{T}_{11,41}$ & 1.0883 & 1.1000 & 1.1000 & 0.9611 \\
\hline $\mathrm{T}_{11,43}$ & 1.0154 & 1.0766 & 1.0321 & 1.0364 \\
\hline $\mathrm{T}_{13,49}$ & 1.0863 & 0.9103 & 1.1000 & 1.1000 \\
\hline $\mathrm{T}_{14,46}$ & 0.9000 & 0.9499 & 1.0583 & 1.0739 \\
\hline $\mathrm{T}_{15,45}$ & 0.9994 & 0.9912 & 1.0289 & 0.9000 \\
\hline $\mathrm{T}_{20,21}$ & 0.9643 & 1.0711 & 1.0894 & 1.0525 \\
\hline $\mathrm{T}_{24,25}$ & 0.9000 & 0.9707 & 1.0630 & 0.9000 \\
\hline $\mathrm{T}_{24,26}$ & 0.9104 & 1.1000 & 0.9415 & 0.9068 \\
\hline $\mathrm{T}_{32,34}$ & 0.9000 & 0.9034 & 0.9906 & 0.9823 \\
\hline $\mathrm{T}_{39,57}$ & 1.0734 & 0.9555 & 1.0594 & 1.0373 \\
\hline $\mathrm{T}_{40,56}$ & 1.0372 & 0.9000 & 1.0506 & 1.0093 \\
\hline $\mathrm{QC}_{18}$ (MVars) & \multicolumn{4}{|c|}{7.9074} \\
\hline $\mathrm{Qc}_{25}$ (MVars) & \multicolumn{4}{|c|}{5.9000} \\
\hline $\mathrm{QC}_{31}$ (MVars) & \multicolumn{4}{|c|}{8.3926} \\
\hline $\mathrm{QC}_{53}$ (MVars) & \multicolumn{4}{|c|}{0} \\
\hline Losses (MW) & 29.4544 & 30.1549 & 37.2181 & 36.7320 \\
\hline Efficiency (\%) & 94.7100 & 417.0800 & 62.7000 & 96.3300 \\
\hline MW Losses average & \multicolumn{4}{|c|}{33.3898} \\
\hline Efficiency (\%) & \multicolumn{4}{|c|}{98.3356} \\
\hline Mvars deviation & \multicolumn{4}{|c|}{16.7853} \\
\hline
\end{tabular}
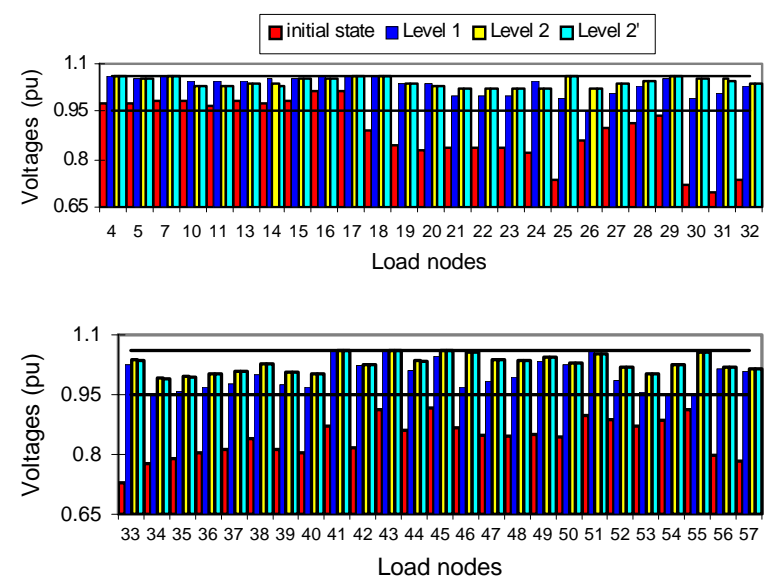

Fig. 4 Load voltages - Phase 1 - Case 1
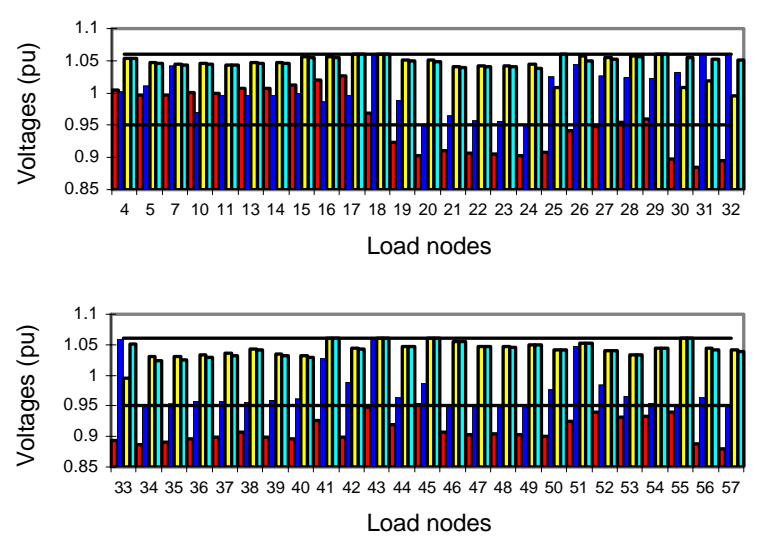

Fig. 5 Load voltages - Phase 1 - Case 2
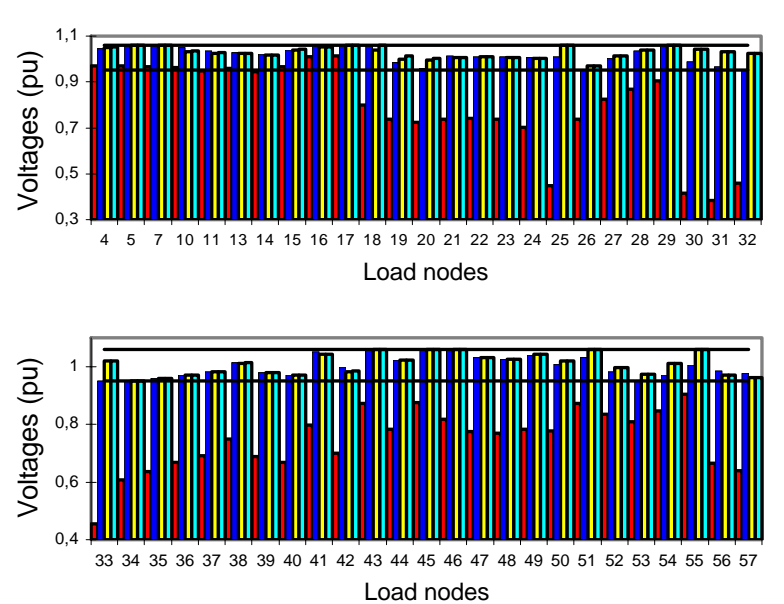

Fig. 6 Load voltages - Phase 1 - Case 3
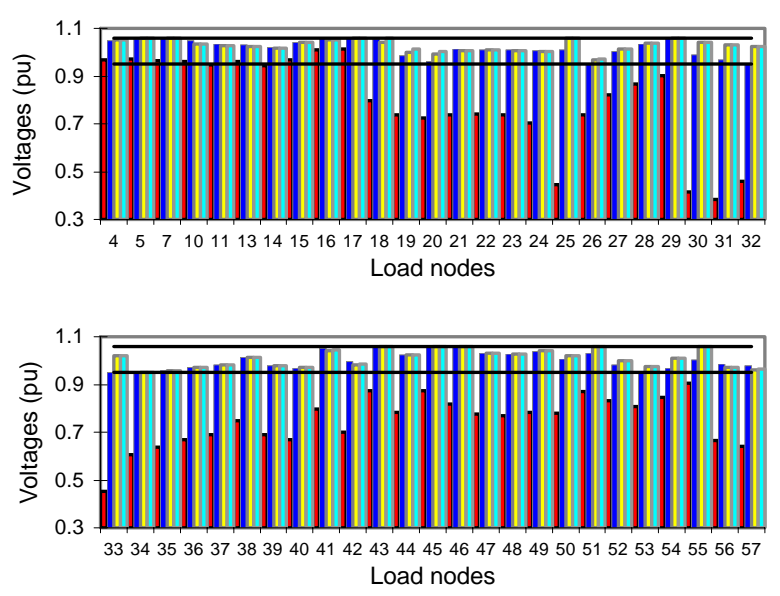

Fig. 7 Load voltages - Phase 1 - Case 4

Level 1 of the program made possible the voltage stabilization within the specified limits compared to the values resulting from the power flow, and the contribution of the reactive compensation optimisation as well as the losses reduction (Fig 8) on the quality of transport of energy is well visible.

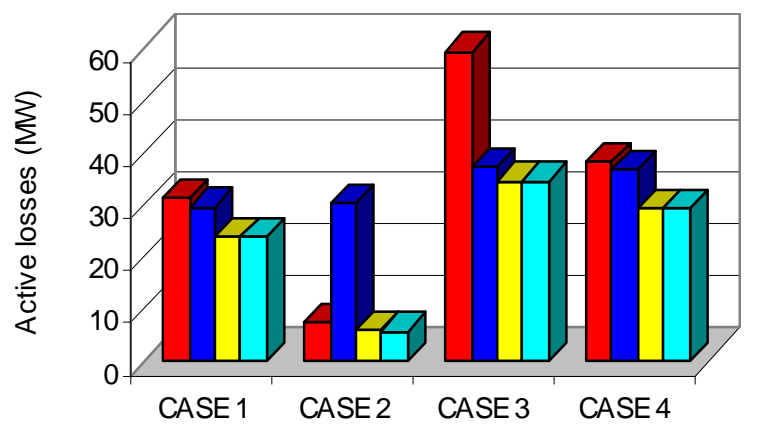

Fig. 8 Initial and final active losses - Phase 1

2) Levels 2 and 2'

The program of level 2 (average losses minimization of all considered study cases) gives results of Table 3. 
TABLE. 3 Optimisation Results - Level 2- Phase 1

\begin{tabular}{|c|c|c|c|c|}
\hline Variables & Case 1 & Case 2 & Case 3 & Case 4 \\
\hline $\mathrm{V}_{\mathrm{G} 1}$ & 1.0875 & 1.0703 & 1.0932 & 1.0979 \\
\hline $\mathrm{V}_{\mathrm{G} 2}$ & 1.0772 & 1.0680 & 1.0742 & 1.0853 \\
\hline $\mathrm{V}_{\mathrm{G} 3}$ & 1.0671 & 1.0585 & 1.0557 & 1.0685 \\
\hline $\mathrm{V}_{\mathrm{G} 6}$ & 1.0600 & 1.0452 & 1.0730 & 1.0571 \\
\hline $\mathrm{V}_{\mathrm{G} 8}$ & 1.0786 & 1.0491 & 1.0865 & 1.0785 \\
\hline $\mathrm{V}_{\mathrm{G} 9}$ & 1.0438 & 1.0449 & 1.0561 & 1.0400 \\
\hline $\mathrm{V}_{\mathrm{G} 12}$ & 1.0456 & 1.0521 & 1.0520 & 1.0363 \\
\hline $\mathrm{T}_{9,55}$ & 1.0226 & 1.0192 & 1.0178 & 1.0230 \\
\hline $\mathrm{T}_{4,18}$ & 1.0644 & 1.0309 & 1.1000 & 1.0658 \\
\hline $\mathrm{T}_{7,29}$ & 1.0088 & 1.0181 & 1.0189 & 1.0101 \\
\hline $\mathrm{T}_{10,51}$ & 1.0247 & 1.0089 & 1.0361 & 1.0238 \\
\hline $\mathrm{T}_{11,41}$ & 1.0932 & 1.0392 & 1.1000 & 1.0971 \\
\hline $\mathrm{T}_{11,43}$ & 1.0290 & 1.0162 & 1.0436 & 1.0330 \\
\hline $\mathrm{T}_{13,49}$ & 1.0607 & 1.0226 & 1.1000 & 1.0597 \\
\hline $\mathrm{T}_{14,46}$ & 1.0295 & 1.0099 & 1.0589 & 1.0291 \\
\hline $\mathrm{T}_{15,45}$ & 1.0097 & 1.0044 & 1.0275 & 1.0097 \\
\hline $\mathrm{T}_{20,21}$ & 0.9990 & 0.9908 & 1.0193 & 1.0050 \\
\hline $\mathrm{T}_{24,25}$ & 1.0070 & 0.9000 & 1.0869 & 1.0096 \\
\hline $\mathrm{T}_{24,26}$ & 0.9976 & 1.0141 & 0.9646 & 0.9989 \\
\hline $\mathrm{T}_{32,34}$ & 0.9662 & 1.0617 & 0.9196 & 0.9642 \\
\hline $\mathrm{T}_{39,57}$ & 1.0442 & 1.0249 & 1.0418 & 1.0487 \\
\hline $\mathrm{T}_{40,56}$ & 1.0230 & 1.0245 & 1.0095 & 1.0276 \\
\hline $\mathrm{Qc}_{18}$ (MVars) & \multicolumn{4}{|c|}{1.1614} \\
\hline $\mathrm{Qc}_{25}$ (MVars) & \multicolumn{4}{|c|}{5.9000} \\
\hline $\mathrm{Qc}_{31}$ (MVars) & \multicolumn{4}{|c|}{8.3926} \\
\hline $\mathrm{QC}_{53}$ (MVars) & \multicolumn{4}{|c|}{0.0000} \\
\hline Losses (MW) & 23.6680 & 5.7577 & 34.5120 & 29.2031 \\
\hline Efficiency (\%) & 76.1000 & 79.6400 & 58.1400 & 76.5900 \\
\hline MW Losses average & \multicolumn{4}{|c|}{23.2852} \\
\hline Efficiency (\%) & \multicolumn{4}{|c|}{68.5766} \\
\hline Mvars deviation & \multicolumn{4}{|c|}{23.5313} \\
\hline
\end{tabular}

These results show that by having 5.9 Mvars on node 25 and 8.39 Mvars on node 31 and that while making commutate the 7.9 Mvars of node 18 to 1.16 Mvars, with the use of all the controllers of a reactive energy, the average of the losses is reduced by $29.76 \%$ compared to level 1. Figures 4-9 display the load nodes voltage values. It is noticed that all voltages lie between their permitted limits.

The application of level 2' (MW losses minimization for separate study cases) gives the results of Table 4, which contains the control variables of the five considered study cases of the network.

This table illustrates the results of a minimization of the active losses of each case of the network, whose average presents a reduction of $29.93 \%$, which is $0.17 \%$ more reduction than that deduced from the second level. The commutation of the bank capacitors is not really significant from the losses point of view (i.e. almost identical to level 2). In general, the application of the $2^{\text {nd }}$ level is necessary insofar as to level 1 , an excess of losses is announced in case 2 about $417 \%$, more especially as the reduction of the losses is very significant there, which presents figure 4.18. It is true that the first level ensures the realisability but stills insufficient in economic perspective.
TABLE. 4 Optimisation Results - Level 2'- Phase 1

\begin{tabular}{|l|l|l|l|l|}
\hline Variables & Case 1 & Case 2 & Case 3 & Case 4 \\
\hline $\mathrm{V}_{\mathrm{G} 1}$ & 1.0874 & 1.0703 & 1.0930 & 1.0980 \\
\hline $\mathrm{V}_{\mathrm{G} 2}$ & 1.0771 & 1.0680 & 1.0745 & 1.0854 \\
\hline $\mathrm{V}_{\mathrm{G} 3}$ & 1.0666 & 1.0585 & 1.0573 & 1.0688 \\
\hline $\mathrm{V}_{\mathrm{G} 6}$ & 1.0598 & 1.0451 & 1.0717 & 1.0578 \\
\hline $\mathrm{V}_{\mathrm{G} 8}$ & 1.0788 & 1.0491 & 1.0872 & 1.0789 \\
\hline $\mathrm{V}_{\mathrm{G} 9}$ & 1.0438 & 1.0445 & 1.0568 & 1.0401 \\
\hline $\mathrm{V}_{\mathrm{G} 12}$ & 1.0456 & 1.0520 & 1.0523 & 1.0363 \\
\hline $\mathrm{T}_{9,55}$ & 1.0228 & 1.0196 & 1.0172 & 1.0228 \\
\hline $\mathrm{T}_{4,18}$ & 1.0563 & 1.0356 & 1.0811 & 1.0722 \\
\hline $\mathrm{T}_{7,29}$ & 1.0091 & 1.0201 & 1.0187 & 1.0099 \\
\hline $\mathrm{T}_{10,51}$ & 1.0247 & 1.0099 & 1.0354 & 1.0239 \\
\hline $\mathrm{T}_{11,41}$ & 1.0950 & 1.0468 & 1.1000 & 1.0984 \\
\hline $\mathrm{T}_{11,43}$ & 1.0292 & 1.0173 & 1.0426 & 1.0330 \\
\hline $\mathrm{T}_{13,49}$ & 1.0614 & 1.0262 & 1.1000 & 1.0603 \\
\hline $\mathrm{T}_{14,46}$ & 1.0300 & 1.0122 & 1.0576 & 1.0294 \\
\hline $\mathrm{T}_{15,45}$ & 1.0103 & 1.0058 & 1.0264 & 1.0098 \\
\hline $\mathrm{T}_{20,21}$ & 1.0001 & 0.9929 & 1.0168 & 1.0046 \\
\hline $\mathrm{T}_{24,25}$ & 1.0173 & 1.0058 & 1.0865 & 1.0182 \\
\hline $\mathrm{T}_{24,26}$ & 0.9976 & 1.0116 & 0.9662 & 0.9987 \\
\hline $\mathrm{T}_{32,34}$ & 0.9584 & 0.9734 & 0.9187 & 0.9578 \\
\hline $\mathrm{T}_{39,57}$ & 1.0442 & 1.0256 & 1.0436 & 1.0486 \\
\hline $\mathrm{T}_{40,56}$ & 1.0209 & 1.0137 & 1.0116 & 1.0258 \\
\hline $\mathrm{Qc}_{18}$ (MVars) & 2.7203 & 0.5512 & 7.9074 & 0.0000 \\
\hline $\mathrm{QC}_{25}$ (MVars) & 5.9000 & 3.7057 & 5.9000 & 5.9000 \\
\hline $\mathrm{Qc}_{31}$ (MVars) & 7.0679 & 2.6976 & 8.3926 & 7.2865 \\
\hline $\mathrm{Losses}$ (MW) & 23.6593 & 5.6224 & 34.4337 & 29.1955 \\
\hline Efficiency (\%) & 76.0700 & 77.7700 & 58.0100 & 76.5700 \\
\hline Mvars deviation & 20.6475 & 20.6408 & 16.7853 & 23.5865 \\
\hline & & & & \\
\hline
\end{tabular}

\section{B. Reactive power sources investment (Phase 2)}

\section{1) A-Level 1}

For phase 2 the level 1, obtained results are presented in Table 5.

TABLE. 5 Optimisation Results - Level 1- Phase 2

\begin{tabular}{|l|l|l|l|l|}
\hline Variables & Case 1 & Case 2 & Case 3 & Case 4 \\
\hline $\mathrm{V}_{\mathrm{G} 1}$ & 1.0802 & 1.0791 & 1.0880 & 1.0831 \\
\hline $\mathrm{V}_{\mathrm{G} 2}$ & 1.0653 & 1.0778 & 1.0701 & 1.0708 \\
\hline $\mathrm{V}_{\mathrm{G} 3}$ & 1.0417 & 1.0587 & 1.0490 & 1.0576 \\
\hline $\mathrm{V}_{\mathrm{G} 6}$ & 1.0504 & 1.0624 & 1.0515 & 1.0463 \\
\hline $\mathrm{V}_{\mathrm{G} 8}$ & 1.1000 & 1.0518 & 1.1000 & 1.0667 \\
\hline $\mathrm{V}_{\mathrm{G} 9}$ & 1.0624 & 1.0377 & 1.0704 & 1.0348 \\
\hline $\mathrm{V}_{\mathrm{G} 12}$ & 1.0609 & 1.0385 & 1.0654 & 1.0692 \\
\hline $\mathrm{T}_{9,55}$ & 0.9060 & 1.0055 & 0.9168 & 1.0195 \\
\hline $\mathrm{T}_{4,18}$ & 0.9556 & 1.0158 & 1.1000 & 1.0514 \\
\hline $\mathrm{T}_{7,29}$ & 1.0208 & 0.9056 & 1.0180 & 0.9116 \\
\hline $\mathrm{T}_{10,51}$ & 0.9000 & 0.9213 & 1.0209 & 1.0239 \\
\hline $\mathrm{T}_{11,41}$ & 1.0361 & 1.0537 & 1.1000 & 1.1000 \\
\hline $\mathrm{T}_{11,43}$ & 1.0066 & 0.9000 & 1.0372 & 0.9614 \\
\hline $\mathrm{T}_{13,49}$ & 1.0723 & 0.9000 & 1.1000 & 1.1000 \\
\hline $\mathrm{T}_{14,46}$ & 0.9000 & 1.0370 & 1.0574 & 1.0444 \\
\hline $\mathrm{T}_{15,45}$ & 1.0085 & 0.9000 & 1.0282 & 1.0190 \\
\hline $\mathrm{T}_{20,21}$ & 1.0327 & 1.0951 & 1.1000 & 1.0965 \\
\hline $\mathrm{T}_{24,25}$ & 0.9986 & 0.9481 & 1.1000 & 0.9283 \\
\hline $\mathrm{T}_{24,26}$ & 0.9205 & 0.9549 & 1.0565 & 1.1000 \\
\hline $\mathrm{T}_{32,34}$ & 0.9497 & 0.9100 & 0.9736 & 0.9000 \\
\hline $\mathrm{T}_{39,57}$ & 1.0632 & 1.0856 & 1.0774 & 0.9000 \\
\hline $\mathrm{T}_{40,56}$ & 0.9000 & 1.0490 & 0.9000 & 1.0959 \\
\hline $\mathrm{Qc}_{30}$ (MVars) & \multicolumn{5}{|c|}{6.8503} \\
\hline Losses (MW) & 31.4371 & 10.6951 & 42.0752 & 39.5931 \\
\hline Efficiency (\%) & 101.0800 & 147.9300 & 70.8800 & 103.8400 \\
\hline MW Losses average & \multicolumn{5}{|c|}{30.9502} \\
\hline Efficiency (\%) & 91.1504 \\
\hline Mvars Investment & \multicolumn{5}{|c|}{6.8503} \\
\hline & \multicolumn{5}{|c|}{} \\
\hline
\end{tabular}


The stability of the system is reached after investment of 6.85 Mvars on node 30. The average of the active losses is reduced of $7.18 \%$, and the variables of control (table 5) all are regulated. The voltages of the load nodes are presented on figures 9 to 12 .

For the two phases, the determination of the nodes candidates to the compensation is made on nearby nodes, which reflects the lack of reactive energy on the level of the zone of nodes 30 and 31. The most unfavorable case is of a uniform increase of $50 \%$ of the load, and the overtaking voltages in the initial state are very significant.

\section{3) Level 2}

The application of the second level to minimize the losses gave the results presented in Table 6.

TABLE. 6 Optimisation Results - Level 2- Phase 2

\begin{tabular}{|l|l|l|l|l|}
\hline Variables & Case 1 & Case 2 & Case 3 & Case 4 \\
\hline $\mathrm{V}_{\mathrm{G} 1}$ & 1.0875 & 1.0703 & 1.0930 & 1.0979 \\
\hline $\mathrm{V}_{\mathrm{G} 2}$ & 1.0766 & 1.0680 & 1.0746 & 1.0847 \\
\hline $\mathrm{V}_{\mathrm{G} 3}$ & 1.0647 & 1.0584 & 1.0578 & 1.0662 \\
\hline $\mathrm{V}_{\mathrm{G} 6}$ & 1.0574 & 1.0453 & 1.0713 & 1.0543 \\
\hline $\mathrm{V}_{\mathrm{G} 8}$ & 1.0771 & 1.0491 & 1.0848 & 1.0768 \\
\hline $\mathrm{V}_{\mathrm{G} 9}$ & 1.0434 & 1.0454 & 1.0559 & 1.0394 \\
\hline $\mathrm{V}_{\mathrm{G} 12}$ & 1.0456 & 1.0521 & 1.0523 & 1.0364 \\
\hline $\mathrm{T}_{9,55}$ & 1.0198 & 1.0159 & 1.0153 & 1.0203 \\
\hline $\mathrm{T}_{4,18}$ & 1.0169 & 0.9799 & 1.0700 & 1.0183 \\
\hline $\mathrm{T}_{7,29}$ & 1.0060 & 1.0120 & 1.0165 & 1.0076 \\
\hline $\mathrm{T}_{10,51}$ & 1.0249 & 1.0090 & 1.0356 & 1.0241 \\
\hline $\mathrm{T}_{11,41}$ & 1.0987 & 1.0430 & 1.1000 & 1.1000 \\
\hline $\mathrm{T}_{11,43}$ & 1.0299 & 1.0162 & 1.0456 & 1.0341 \\
\hline $\mathrm{T}_{13,49}$ & 1.0619 & 1.0226 & 1.1000 & 1.0610 \\
\hline $\mathrm{T}_{14,46}$ & 1.0307 & 1.0101 & 1.0588 & 1.0304 \\
\hline $\mathrm{T}_{15,45}$ & 1.0111 & 1.0043 & 1.0254 & 1.0111 \\
\hline $\mathrm{T}_{20,21}$ & 1.0021 & 0.9922 & 1.0230 & 1.0080 \\
\hline $\mathrm{T}_{24,25}$ & 0.9794 & 0.9000 & 1.0680 & 0.9823 \\
\hline $\mathrm{T}_{24,26}$ & 0.9972 & 1.0107 & 0.9603 & 0.9984 \\
\hline $\mathrm{T}_{32,34}$ & 0.9477 & 1.0010 & 0.9283 & 0.9461 \\
\hline $\mathrm{T}_{39,57}$ & 1.0448 & 1.0263 & 1.0278 & 1.0506 \\
\hline $\mathrm{T}_{40,56}$ & 1.0159 & 1.0170 & 0.9838 & 1.0227 \\
\hline $\mathrm{Q}_{30}$ (MVars) & \multicolumn{5}{|c|}{6.8503} \\
\hline Losses (MW) & 23.5289 & 5.6889 & 34.2892 & 29.0796 \\
\hline Efficiency (\%) & 75.6600 & 78.6900 & 57.7600 & 76.2600 \\
\hline MW Losses average $^{|5|} 23.1466$ \\
\hline Efficiency (\%) & \multicolumn{5}{|c|}{6.8503} \\
\hline Mvars Investment & \multicolumn{5}{|c|}{} \\
\hline
\end{tabular}
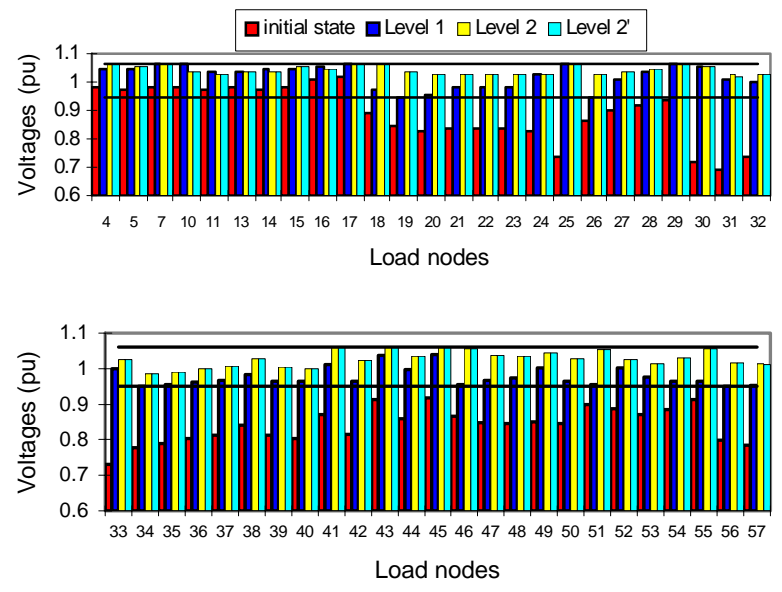

Fig. 9 Load voltages - Phase 2 - Case 1
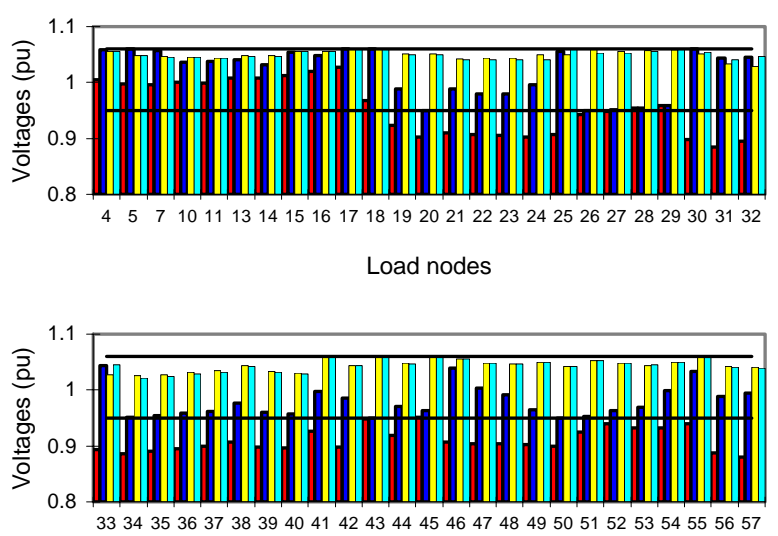

Load nodes

Fig. 10 Load voltages - Phase 2 - Case
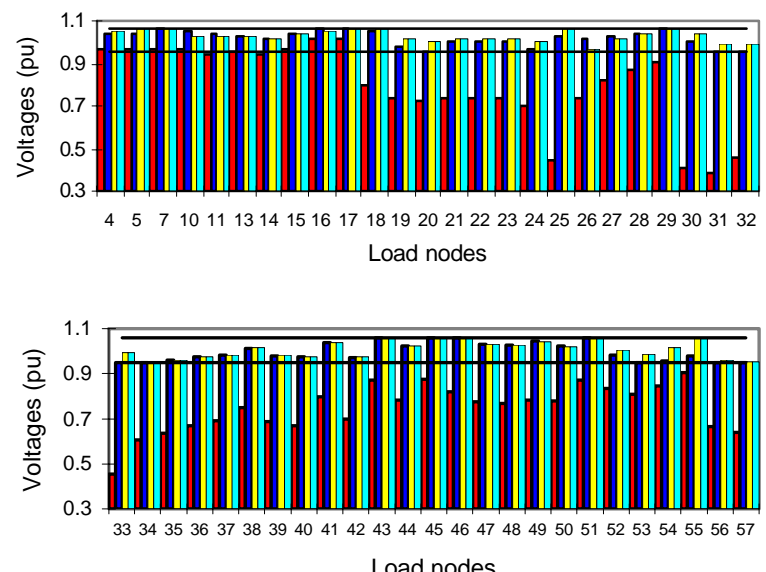

Load nodes

Fig. 11 Load voltages - Phase 2 - Case 3
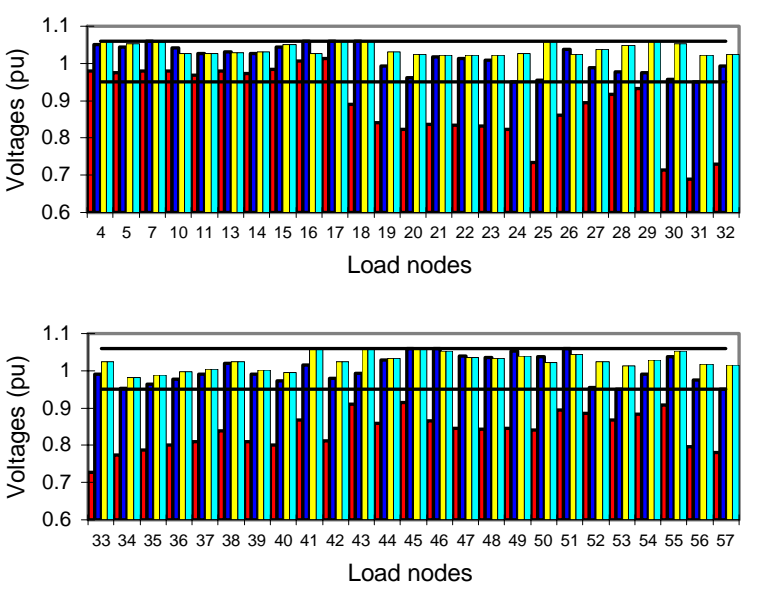

Fig. 12 Load voltages - Phase 2 - Case 4

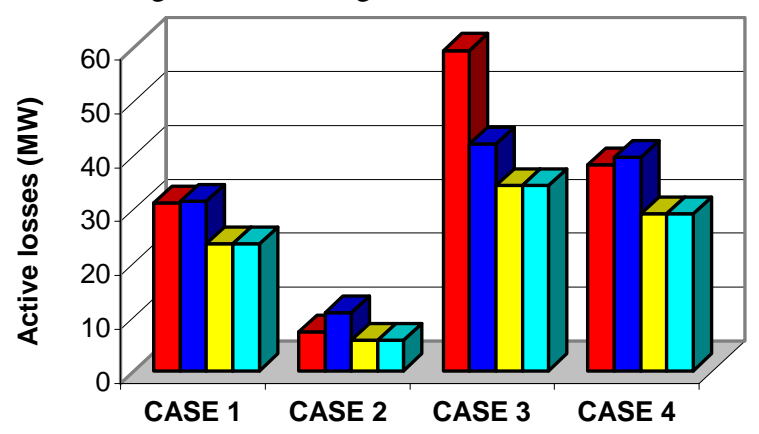

Fig. 13 Initial and final active losses - Phase 2 
Figures 9-12, the values of the voltages to the nodes of load on level 2 and 2' are also presented. We note that all these sizes are always in the intervals but more or less higher than those of the $1^{\text {st }}$ level (for case 3 , they are almost the same ones), and that the tensions of these two levels are roughly equal. The application of the second phase brought a profit on the average of the losses of $30.17 \%$ (level 2), and 30.23 \% (level 2').

\section{Average losses minimization (Phase 3. Level 2)}

The results illustrate the effect of over-compensation in reactive energy within an electrical supply network, with a minimization of the average of the losses equal to $33.67 \%$. We also note that the output of the losses for the $2^{\text {nd }}$ case $(85.31 \%)$ is higher than that of the preceding phases $(79.64 \%, 78.69 \%)$, which means that the choice of the average of the losses like objective function, does not offer the optimum of each case separately, but allows to include all the cases in the same problem.

However, it was foreseeable that the third phase minimizes the average of the losses better that phases 1 and 2. $\mathrm{N}$ the other hand, over-compensation harms the quality of energy knowing that the capacitor batteries generate harmful harmonics for the network. In conclusion, the results of application of the three phases on the network IEEE 57 buses enable us to note that the second phase offers better results concerning the investment and the losses.

\section{Conclusion}

This work was directed to apply a new reactive power sources distribution strategy to the Algerian Electrical Power System. The methodology was based on a first phase concerning an optimal movement of the existing reactive power source devices, a second phase devoted to the investment of new reactive sources and a phase 3 supporting the optimization of the average of the losses considering the minimum compensation through movement or investment.

The solution of the global non-linear problem is performed using the projected and augmented Lagrange method associated with the reduced gradient method and the DFP Quasi Newton technique.

The simulation tests showed the advantage of a two levels procedure., considering an initial minimal compensation before minimizing the active losses. The first two phases, movement of the existing compensation sources and investment of new devices, gave distinct solutions with the same compensation nodes candidates and a clear losses reduction. The main objectives were achieved as the voltage amplitudes were brought to their range limits. The voltage and tap ratio transformers adjustment depend on the bank capacitors location. The power system behaviour for the different studied cases varies according to the objective function (phase), its size and structure. The movement can satisfy most of the network changes (or outages). However, before choosing a movement action, one should insure that it is applicable for various cases, which require separate simulations by taking the compensators corresponding to the most severe constraints as being fixed or commutable.

\section{References}

[1] M.Belazzoug, "Répartition Optimale des Sources de Puissance Réactive dans un Réseau Electrique“, Master thesis, Polytechnic National School, Algeria, 2001.

[2] V.H.Quintana, M.Santos-Nieto, A.R.Conn, "Solving Reactive Power Dispatch by a Penality function/linear programming method”. Canadian Journal of Electrical and Computer Engineering, Vol.15, Issue 2, May 1990, Canada, pp.63-72.

[3] J.D.Weber, "Implementation of Newton-Based Optimal Power Flow into a Power System Simulation Environment.” Thesis PhD, University of Illinois, USA, 1997.

[4] Hua Wei, H.Sasaki, J.Kubukawa, R.Yokohama, “An Interior Point Nonlinear Programming for Optimal Power Flow Problems with A Novel Data Structure". IEEE Trans on PAS, Vol.13, No 3, August 1998, pp.870-883.

[5] B.A.Hughes, G.Jee, R.R.Shoults, "Optimal Reactive Power Planning”. IEEE Trans on PAS -100, Vol .90 ,No 05, May 1981, pp. 2189-2196.

[6] N.Deeb, S.M.Shahidehpour, "Linear Reactive Power optimisation in a large power network using the decomposition approach Wholfe Dantzig.”. IEEE Trans on PAS, Vol .5, Issue 2, May 1990, pp.428-438. 